\title{
Role of salinity in the susceptibility of eelgrass Zostera marina to the wasting disease pathogen Labyrinthula zosterae
}

\author{
Katie L. McKone, Christopher E. Tanner* \\ Department of Biology, 18952 E. Fisher Rd., St. Mary's College of Maryland, St. Mary's City, Maryland 20686, USA
}

\begin{abstract}
Eelgrass wasting disease, caused by the net-forming protist Labyrinthula zosterae, is suspected as the causative agent in the North Atlantic population declines of the temperate seagrass Zostera marina in the 1930s, as well as in more recent localized die-offs. During these declines, populations of eelgrass in low salinity areas were less likely to decline and quicker to recover. The goal of this study was to understand the relationships between eelgrass wasting disease and salinity, and how phenolic acids, putative plant defense compounds, varied with salinity and infection. We studied these relationships through mesocosm experiments in which eelgrass shoots were inoculated with $L$. zosterae under different salinity treatments $(5,10,15,25$ and 40). We used lesion area as a measure of the degree of infection. Phenolic acids were separated and quantified with reversed phase HPLC. Three phenolic acids, rosmarinic, gallic and ferulic, were identified in leaf and rhizome tissue. Lesion area decreased with a decrease in salinity, and the concentration of phenolic acids increased with lesion area in inoculated leaves. Concentrations of phenolic acids were not good predictors of resistance to $L$. zosterae infection. Our study supports the hypothesis that observed decreases in eelgrass wasting disease in low salinity areas are due to the inhibition of L. zosterae at lower salinities.
\end{abstract}

KEY WORDS: Eelgrass $\cdot$ Zostera marina $\cdot$ Wasting disease $\cdot$ Labyrinthula $\cdot$ Salinity $\cdot$ Phenolic acid

\section{INTRODUCTION}

Labyrinthula spp. are net-forming straminipilan protists (Raghukumar 2002) usually found in association with seagrasses and macroalgae in coastal waters around the world (Muehlstein et al. 1991, Vergeer \& den Hartog 1994). Labyrinthula spp. can be primary pathogens, causing wasting disease in several seagrass species, including Zostera marina (Short et al. 1987, Muehlstein et al. 1991, Ralph \& Short 2002) and Thalassia testudinum (Blakesley et al. 2001, Steele et al. 2005).

In particular, Labyrinthula zosterae Porter et Muehlstein (Muehlstein et al. 1988, 1991) has been implicated in the mass mortality of eelgrass in the North Atlantic in the 1930 s, during which $>90 \%$ of eelgrass populations disappeared in Europe and North Amer- ica, and in more localized declines in Maine, New Hampshire and Massachusetts in the 1980s (Short et al. 1987, 1988, Burdick et al. 1993). In these mass mortalities, eelgrass was least affected and recovered more quickly in areas with reduced salinities (Stevens et al. 1950, Rasmussen 1977, den Hartog 1987, Short et al. 1988). In his survey of eelgrass beds at Cape Ann, Massachusetts between 1933 and 1984, Dexter (1985) reported that the greatest declines of eelgrass occurred during periods of drought. These observations suggest that higher salinities either increase the virulence of $L$. zosterae or reduce the disease resistance in eelgrass.

Several studies provide more insight into the effect of salinity on the virulence of Labyrinthula zosterae and wasting disease symptoms. Using hanging drop cultures, Young (1943) observed that, while Laby- 
rinthula sp. isolated from Zostera marina survived in salinities ranging from freshwater to double that of normal seawater, the ectoplasmic network holding L. zosterae cells together was weakened at lower salinities. Muehlstein et al. (1988) found that Labyrinthula sp. isolated from $Z$. marina grew on serum seawater agar plates with salinities of 15 and 20 while it showed variable growth at 10 and no growth at 0 and 5. When eelgrass shoots were held at different salinities $(10,14$ and 26) in flasks and inoculated with Labyrinthula sp., $100 \%$ of the plants showed disease symptoms at salinities of 14 and above, and 0 and $17 \%$ of plants from 2 different isolates showed symptoms at a salinity of 10 (Muehlstein et al. 1988). Short et al. (1988) noted that infection did not spread among eelgrass shoots grown in tanks with salinities less than 10, whereas the infection did spread among eelgrass shoots in tanks with salinities of 15 to 30. Burdick et al. (1993) observed a positive relationship between wasting disease index and salinity both in the field and in mesocosms. A salinity of 20 appeared to be the lower limit for rapid spread of wasting disease in the field, whereas a salinity of 25 appeared to be the lower limit in the higher-light conditions of mesocosms. These studies suggest that both the growth of $L$. zosterae and its ability to infect eelgrass are limited by lower salinities.

A possible contributing factor to the ability of Labyrinthula zosterae to infect eelgrass is the influence of salinity on the resistance of eelgrass to wasting disease. Although eelgrass has a broad salinity tolerance (den Hartog 1970), higher salinities can have negative effects on the photosynthesis, production and overall vitality of at least some populations of eelgrass (Kamermans et al. 1999, van Katwijk et al. 1999). Rasmussen (1977) suggested that the optimal conditions for eelgrass at lower salinities could result in increased resistance to wasting disease.

Labyrinthula zosterae is likely a widespread parasite or saprophyte of eelgrass that, when disease resistance in the host is reduced in response to environmental stress, can become a primary pathogen (Short et al. 1988, Vergeer \& den Hartog 1994, Ralph \& Short 2002). One of the ways that seagrasses may resist pathogens is by the production of phenolic compounds (Harrison 1982, Buchsbaum et al. 1990, Arnold \& Targett 2002). Eelgrass is rich in phenolic acids, which in many plant species provide disease resistance or are intermediates in the synthesis of other antimicrobial compounds (Levin 1971, Nicholson \& Hammerschmidt 1992, Sarma \& Singh 2003). Phenolic acids reported for eelgrass include caffeic, chlorogenic, gallic, gentisic, ferulic, protocatechuic, $p$-coumaric, $p$-hydroxybenzoic, rosmarinic and vanillic acids (Zapata \& McMillan 1979, Quackenbush et al. 1986, Ravn et al. 1994, Milkova et al. 1995, Vergeer \& Develi 1997). In eelgrass, phenolic compounds may inhibit bacteria and other pathogens (Harrison 1982), and at least one phenolic acid (caffeic acid) has been observed to inhibit Labyrinthula sp. in culture (Vergeer \& Develi 1997). However, phenolic acids may require modification to be biologically active. Todd et al. (1993) found that $p$-sulfoxy cinnamic acid isolated from eelgrass inhibited the attachment of marine bacteria and barnacles, but that the nonsulfated phenolic acid precursors were ineffective. The tropical seagrass Thalassia testudinum produces a sulfated flavone glycoside that, in natural concentrations, inhibits the growth of Schizochytrium aggregatum, a thraustochytrid protist related to Labyrinthula (Jensen et al. 1998).

Concentrations of phenolic compounds vary within eelgrass as a result of both intrinsic and extrinsic factors. Actively growing tissues (primary leaves, rhizomes) have higher levels than older, senescent tissues (secondary and tertiary leaves) (Ravn et al. 1994). Concentrations also vary seasonally, with the highest levels occurring during the time of year when plants are most actively growing (Harrison \& Durance 1989, Ravn et al. 1994). High nutrient concentrations are suggested to both inhibit (Buchsbaum et al. 1990) and promote (Ravn et al. 1994) the production of phenolic compounds, and Vergeer et al. (1995) reported that high irradiances increased phenol levels, while elevated temperatures $\left(25\right.$ vs. $15^{\circ} \mathrm{C}$ ) resulted in decreased phenol levels. However, Vergeer et al. (1995) did not see a salinity effect on phenolic compounds in eelgrass. Indirect evidence that variation in phenolic levels as a result of environmental factors can play a role in resistance to wasting disease comes from the study of Buchsbaum et al. (1990), in which plants grown in nitrogen-rich mud had a lower phenolic content than plants grown in sand and were more susceptible to wasting disease. The presence of wasting disease may increase the production of phenolic acids in eelgrass, as has been seen in the response of other plants to infection (Levin 1971, Sarma \& Singh 2003). Vergeer et al. (1995) observed elevated total phenolic concentrations adjacent to wasting disease lesions in eelgrass, and Vergeer \& Develi (1997) reported higher levels of phenolic acids in field-collected leaves with lesions than in leaves without lesions.

The evidence provided by these studies suggests that low salinities inhibit the eelgrass wasting disease pathogen Labyrinthula zosterae; however, the effect of salinity and the pathogen itself on the disease resistance of Zostera marina is more speculative. To investigate further the interaction between salinity, phenolic compounds and wasting disease, studies were carried out on eelgrass under controlled conditions in replicate mesocosms. 


\section{MATERIALS AND METHODS}

Source of plants. Zostera marina shoots were collected from a bed at the mouth of the Big Annemessex River, Maryland, USA $\left(38^{\circ} 01.644^{\prime} \mathrm{N}\right.$ and $\left.75^{\circ} 50.825^{\prime} \mathrm{W}\right)$, in June 2005. Plants were held under natural lighting in aerated estuarine water with a salinity of 22 (same salinity as at the collection site) before being placed into experimental mesocosm tanks for Expt 1.

A second experiment, using eelgrass grown from seed in an aquaculture system, was conducted in January 2006. Culture plants were used in place of field-collected plants for Expt 2 because of the difficulty of collecting plants in the winter and because cultured plants could be grown and maintained at temperatures close to those used in the experiment. Seeds were collected in the spring of 2005 in the same general location where plants were collected for Expt 1. After germination, seedlings were grown in natural estuarine sediments in tanks with recirculated estuarine water under controlled temperatures ranging from 14 to $21^{\circ} \mathrm{C}$, a salinity of 21 and constant light from metal halide lamps with photon irradiances ranging from 50 to $150 \mu \mathrm{mol}$ photons $\mathrm{m}^{-2} \mathrm{~s}^{-1}$. In November plants were transferred to a greenhouse culture system with similar conditions except that natural lighting was supplemented with metal halide lamps that maintained the light in the greenhouse over $150 \mu \mathrm{mol}$ photons $\mathrm{m}^{-2} \mathrm{~s}^{-1}$ during a $12 \mathrm{~h}$ light:12 $\mathrm{h}$ dark photoperiod. Plants were grown in the greenhouse until they were harvested for use in Expt 2.

Isolation, culturing and inoculation. An isolate of Labyrinthula zosterae, from the Chesapeake Bay, was received from the laboratory of Anne Boettcher at the University of South Alabama. To confirm that the isolate was pathogenic, eelgrass was inoculated with L. zosterae, which was then re-isolated from the infected leaves $5 \mathrm{~d}$ after inoculation (Muehlstein et al. 1988). To isolate $L$. zosterae, leaves with black lesions were cut at the edge of the lesion into 1 to $2 \mathrm{~cm}$ pieces. These pieces were surface sterilized by agitation in $0.5 \%$ sodium hypochlorite for $2 \mathrm{~min}$, and rinsed in sterilized distilled water and then sterilized seawater for 2 min each. The leaf pieces were then plated onto horse serum seawater agar plates containing the antibiotics penicillin and streptomycin at concentrations of $0.25 \mathrm{~g} \mathrm{l}^{-1}$ (Muehlstein et al. 1988). The presence of $L$. zosterae on the plates was confirmed by microscopic examination after approximately 1 wk. The pathogen was maintained by weekly transfer to fresh serum seawater agar plates.

For infection experiments, vectors were made from $1 \mathrm{~cm}$ pieces of eelgrass leaves that were autoclaved to eliminate the possible presence of pathogens and to prevent contamination of inoculation cultures (Muehlstein et al. 1988). Sterile leaf pieces were placed on plates containing 1 wk-old Labyrinthula zosterae cul- tures and incubated for $5 \mathrm{~d}$. Control vectors were placed on agar plates that had not been inoculated with $L$. zosterae. Each vector was placed $5 \mathrm{~cm}$ above the rhizome on the secondary leaf of a Zostera marina shoot and clamped to the leaf with sterilized, rigid split Tygon $(1 \times 0.5 \mathrm{~cm}$ in diameter) (Muehlstein et al. 1988).

Experiments. Experiments were conducted in 321 cylindrical fiberglass tanks (30 cm in diameter $\times 45 \mathrm{~cm}$ ) located in a temperature-controlled room kept at $22^{\circ} \mathrm{C}$ with a photoperiod of $12 \mathrm{~h}$ light: $12 \mathrm{~h}$ dark and photon irradiance of 150 to $200 \mu \mathrm{mol}$ photons $\mathrm{m}^{-2} \mathrm{~s}^{-1}$. Illumination was provided by overhead very high output actinic white bulbs with IceCap ${ }^{\mathrm{TM}}$ ballasts. Salinities were adjusted by adding either deionized water or sea salt (Instant Ocean ${ }^{\circledR}$ ) to water from the St. Mary's River estuary. Fifteen bare-root shoots with rhizomes from 2 to $8 \mathrm{~cm}$ long were placed in each of 20 aerated tanks, with groups of 3 plants attached by their rhizomes to concrete disks $(4.2 \mathrm{~cm}$ in diameter $\times 1.8 \mathrm{~cm})$ with rubber bands.

During a preliminary experiment (Expt 1) in the summer of 2005, we compared infection rates and phenolic acid concentrations at a salinity (10) near the lower salinity limit for eelgrass (Pinnerup 1980), and which is associated with variable rates of infection (Muehlstein et al. 1988, Short et al. 1988), to a salinity (25) optimal for eelgrass vitality (Kamermans et al. 1999, van Katwijk et al. 1999). The 4 treatments (5 replicate mesocosms for each) were salinities of 10 and 25 with uninfected plants (controls), and salinities of 10 and 25 with infected plants. Plants acclimated to the water in the tanks for $4 \mathrm{~d}$, at which point water in the system was changed. On the 5th day, control vectors and vectors containing Labyrinthula zosterae were clamped on the secondary leaves, and the plants were placed back in their appropriate treatment. After a 5 d infection period, plants were harvested for analyses.

A second experiment (Expt 2) was conducted in the winter of 2006 to study lesion area and eelgrass phenolic acid content over a broad range of salinities $(5,15,25$ and 40) representing the range of tolerance for eelgrass (den Hartog 1970, Giesen et al. 1990). Plants were acclimated to the salinity treatments (5 replicate mesocosms for each) for $4 \mathrm{~d}$. On the 5 th day, water in the system was changed and 5 plants from each tank were harvested and processed to determine the effect of salinity on phenolic acids. The other 10 plants received vectors containing Labyrinthula zosterae and were placed back in their appropriate treatment. After a $5 \mathrm{~d}$ infection period, plants were harvested for analyses.

Processing of samples. Lesion area is an observable proxy for the degree and rate of an infection by Labyrinthula zosterae (Burdick et al. 1993, Steele et al. 2005). To analyze lesion area, leaves were scanned with a flat-bed scanner and the lesion area was quan- 
tified using ImageJ software (National Institutes of Health). The statistical software SAS 9.1 was used for all statistical analyses. ANOVAs with an F-test were used to determine treatment effects, and linear regression analysis was used to test for a linear relationship between salinity and lesion area in Expt 2.

For tissue analyses, plant material in each tank was pooled. The secondary leaf was separated into the tissue 0 to $2 \mathrm{~cm}$ above and below the area of infection or, if no infection was present, from above and below the vector, and processed for the analysis of phenolic acids. In Expt 2, tissue from the primary leaves and rhizome was included in the analyses to look at upregulation in the production of phenolic compounds distant from site of infection. All tissue was flash frozen in liquid nitrogen and stored at $-80^{\circ} \mathrm{C}$.

Phenolic acids. Phenolic acids were quantified by reversed phase HPLC using methods modified from Ravn et al. (1994) and Steele et al. (2005). Eelgrass tissue samples (10 to $80 \mathrm{mg}$ ) were ground in liquid nitrogen, and phenolic compounds were extracted from the tissue in extraction solvent (1:1 methanol:2\% acetic acid) at a ratio of $20 \mu \mathrm{l}$ of solvent per $1 \mathrm{mg}$ of tissue. Tissue in the extraction solvent was sonicated for $30 \mathrm{~min}$ in ice water and then gently shaken overnight in a $3^{\circ} \mathrm{C}$ temperature-controlled room. Samples were spun in an Eppendorf 5415R centrifuge at maximum rpm for $10 \mathrm{~min}$ at $3^{\circ} \mathrm{C}$, and $10 \mu \mathrm{l}$ supernatant samples were injected into a Lab Alliance Series III HPLC with a Discovery 18 guard column (Supleguard; $2 \mathrm{~cm} \times 4.00 \mathrm{~mm}$, $5 \mu \mathrm{m}$ ) and Discovery C18 column (Supleco; $25 \mathrm{~cm} \times$ $4.6 \mathrm{~mm}, 5 \mu \mathrm{m})$. A flow-through solvent of 1:1:10 HPLC grade methanol, 2-propanol and $2 \%$ acetic acid was

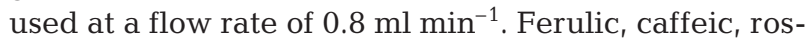
marinic and gallic acid peaks were measured using a Lab Alliance spectrophotometer (Model 500) set at a wavelength of $330 \mathrm{~nm}$ and were compared to commercial standards (Sigma). Two-factor ANOVAs and Ftests were used to analyze changes in phenolic acids in relation to salinity and infection in Expts 1 and 2. For Expt 2 a linear regression analysis was used to test for a linear relationship between lesion area and phenolic acids. Because the distributions of phenolic acid data for the secondary leaf in Expt 2 were not normal, an arcsine square root transformation was performed prior to statistical analyses.

\section{RESULTS}

\section{Salinity and infection}

Lesions that resulted from Labyrinthula zosterae infection were dark black and had distinct margins bordered by green tissue. At the beginning stages of an infection, lesions occurred along the edge of the leaf only. As the infection spread, lesions moved away from the inoculum along the edge of the leaf in both directions and moved inward such that the lesions separated the base and tip of the infected leaf. In both experiments, L. zosterae was re-isolated from these distinct black lesions to verify the source of infection (Koch's postulate; see Short et al. 1987).

Inoculated plants held at lower salinities were healthy and lacked lesions, with the exception of a few brown spots beneath or adjacent to the point of inoculation. These were presumably a result of the clamp used to attach the vector and were not indicative of infection by Labyrinthula zosterae at salinities of 5 and 10 (Figs. 1 \& 2). Plants inoculated at higher salinities contained black lesions typical of L. zosterae (Muehlstein et al. 1988, Muehlstein et al. 1991) covering most of the secondary leaf; these black lesions accounted for

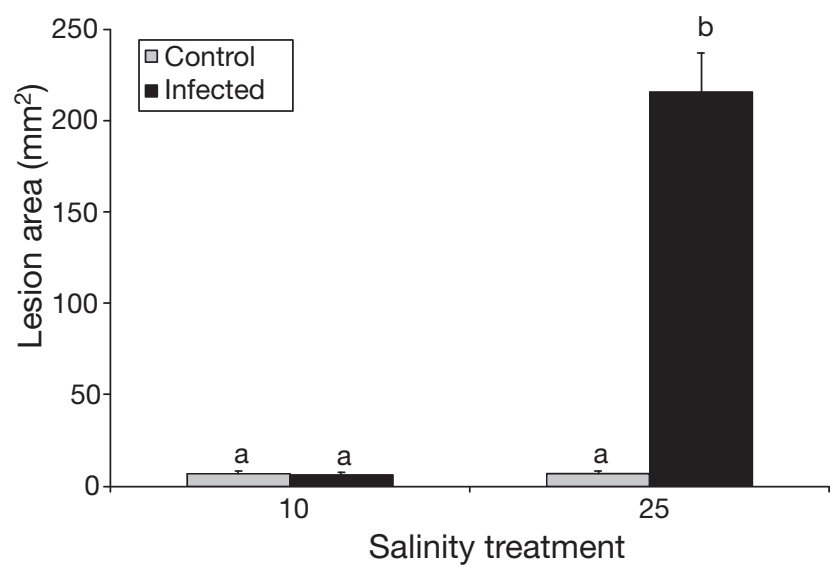

Fig. 1. Zostera marina. Lesion areas for secondary leaves infected with Labyrinthula zosterae in Expt 1. Letters above error bars indicate significant differences $(p<0.001$; mean \pm $\mathrm{SE}, \mathrm{n}=5$ )

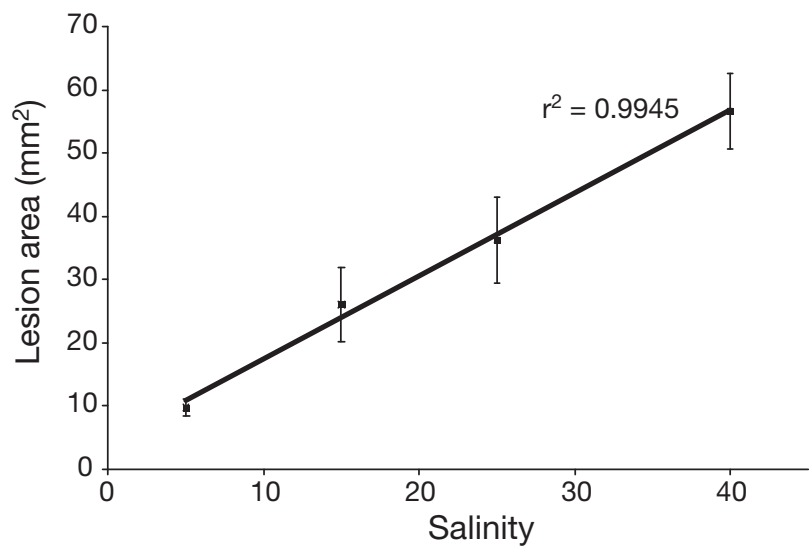

Fig. 2. Zostera marina. Lesion area of secondary leaves infected with Labyrinthula zosterae at salinities 5, 15, 25 and 40 in Expt 2. Linear regression shows significant difference at $\mathrm{p}<0.001($ mean $\pm \mathrm{SE}, \mathrm{n}=5)$ 
the lesion areas reported at salinities of 15 and higher (Figs. $1 \& 2$ ). Not only did the plants inoculated at salinities of 15 and higher contain lesions typical of a L. zosterae infection, a positive linear relationship between salinity and lesion area was also observed (regression analysis, $\mathrm{r}^{2}=0.9945, \mathrm{p}<0.001$ ) in Expt 2 (Fig. 2).

\section{Phenolic acids}

Of the 4 phenolic acid standards run on the HPLC, ferulic, gallic and rosmarinic acids were present in the secondary and primary leaves, with gallic acid occurring at the highest concentration. In the rhizome, gallic and rosmarinic acids were found in similar concentrations, and ferulic acid was found in very low concentrations and not included in the rhizome analysis. Only trace amounts of caffeic acid were found, so this phenolic acid was not included in the analysis. There were no significant differences between phenolic acid concentrations above and below lesions, so values were averaged for each replicate.

In Expt 1, there was a significant interaction in \% phenolic acids between salinity and infection treatments (2-factor ANOVA, p = 0.027). Infection with Labyrinthula zosterae had no effect on phenolic acid content at a salinity of 10 , but resulted in significantly higher combined phenolic acids at a salinity of 25 relative to the control plants kept at the same salinity (Fig. 3). However, the phenolic acid content of the plants infected at a salinity of 25 was not significantly different from those infected at a salinity of 10, despite the larger lesion area experienced by the plants kept at 25 (Fig. 3).

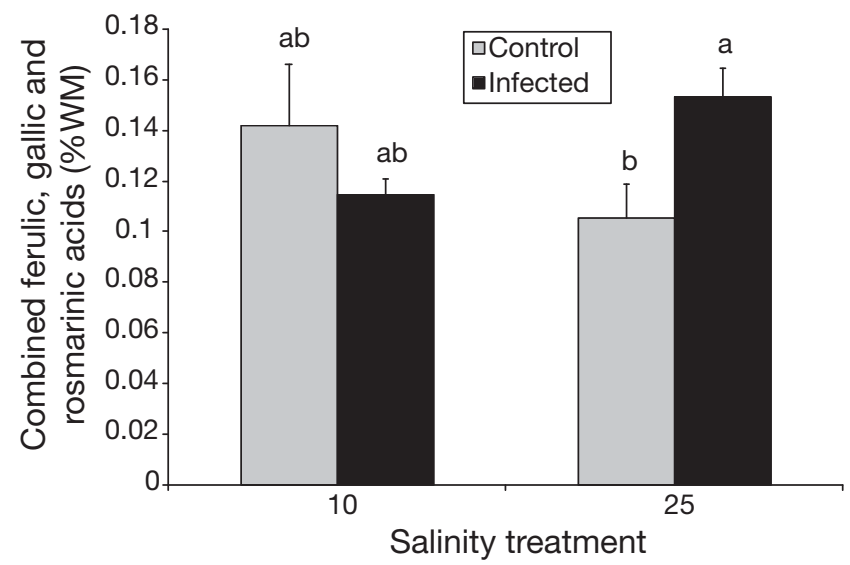

Fig. 3. Zostera marina. Gallic, ferulic and rosmarinic acid content $(\%)$ in wet mass (WM) found in secondary leaves that received control vectors (control) or vectors inoculated with Labyrinthula zosterae (infected) in Expt 1. Letters above error bars indicate significant differences $(p<0.05$; mean \pm $\mathrm{SE}, \mathrm{n}=5$ )
In Expt 2, we did not observe an interaction between salinity and infection in the secondary leaf (2-factor ANOVA, $p=0.324)$. There was a significant increase in combined phenolic acid content of the secondary leaf with increasing lesion size, which accompanied an increase in salinity (2-factor ANOVA, p = 0.012; Fig. 4). The phenolic acid content of the inoculated leaves at a salinity of 40 was 3 times higher than that of the control leaves and the inoculated leaves at a salinity of 5. Furthermore, a positive linear relationship was found between increasing lesion area and combined phenolic acids (regression analysis, $r^{2}=0.9473, p=0.002$; Fig. 5). As with the secondary leaf, there was no interaction between salinity and infection for the rhizome tissue, but there was a significant increase in phenolic acid content of response to infection (2-factor ANOVA, p = 0.004). Specifically, phenolic acid content of infected

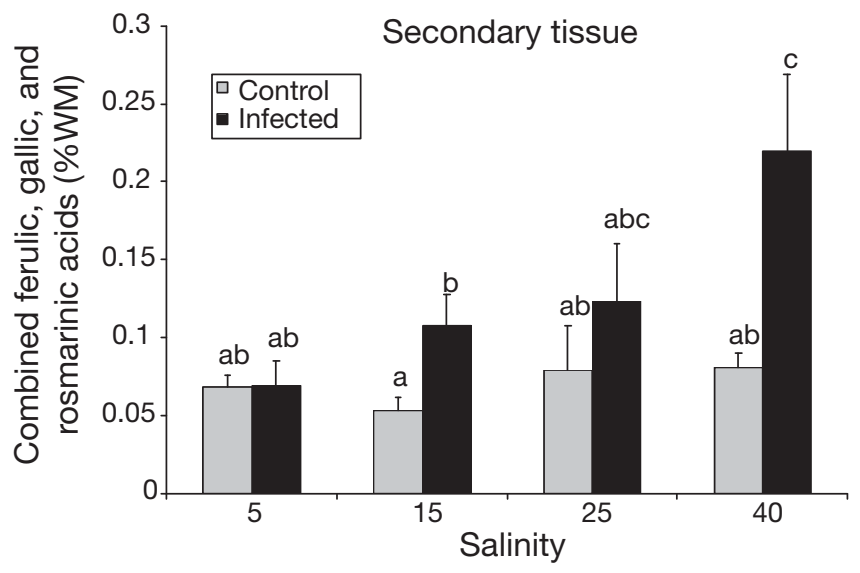

Fig. 4. Zostera marina. Gallic, ferulic and rosmarinic acid content $(\%)$ in wet mass (WM) of secondary leaves that received control vectors (control) or vectors inoculated with Labyrinthula zosterae (infected) in Expt 2. Letters above error bars indicate significant differences $(\mathrm{p}<0.05$; mean $\pm \mathrm{SE}, \mathrm{n}=3$ to 5$)$

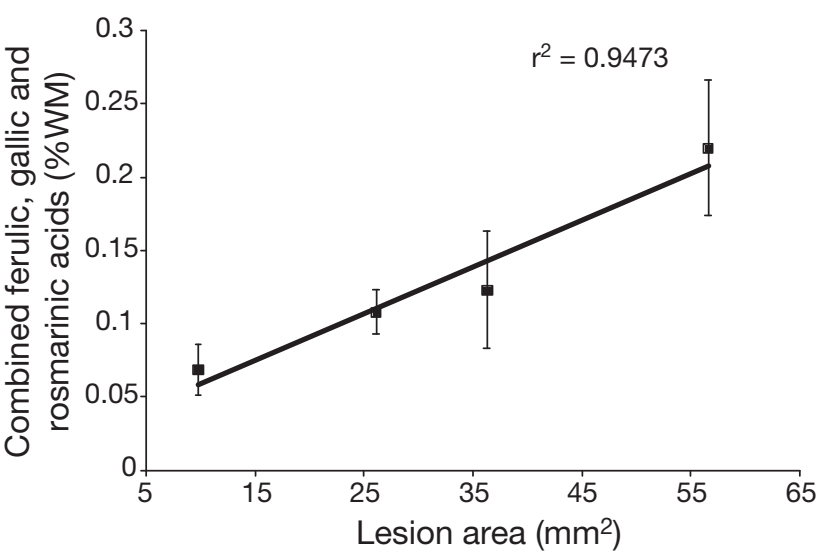

Fig. 5. Zostera marina. Gallic, ferulic and rosmarinic acid content (\%) plotted against the lesion area from Expt 2. Linear regression analysis gave $\mathrm{p}<0.05$ (mean $\pm \mathrm{SE}, \mathrm{n}=3$ to 5 ) 


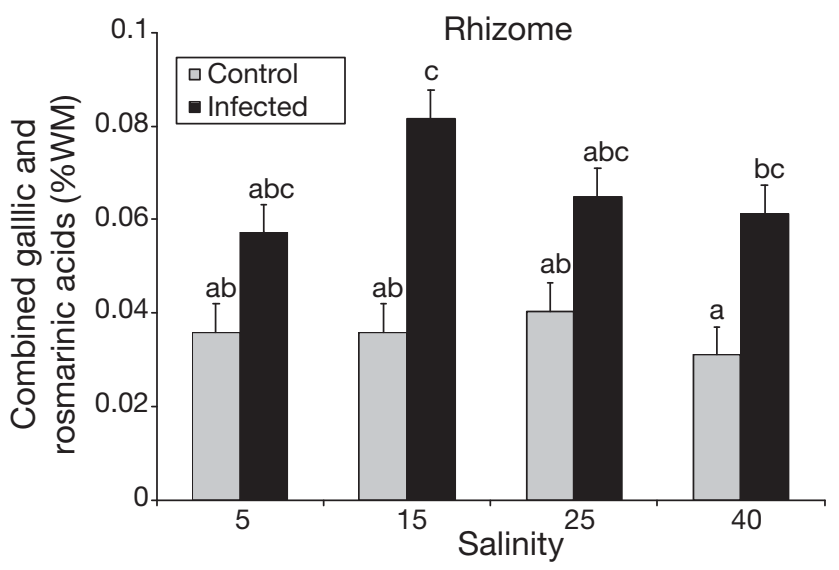

Fig. 6. Zostera marina. Gallic and rosmarinic acid content (\%) in wet mass (WM) of rhizome tissue from plants that received control vectors (control) or vectors inoculated with Labyrinthula zosterae (infected) in Expt 2. Letters above error bars indicate significant differences $(\mathrm{p}<0.05$; mean $\pm \mathrm{SE}, \mathrm{n}=3$ to 5$)$

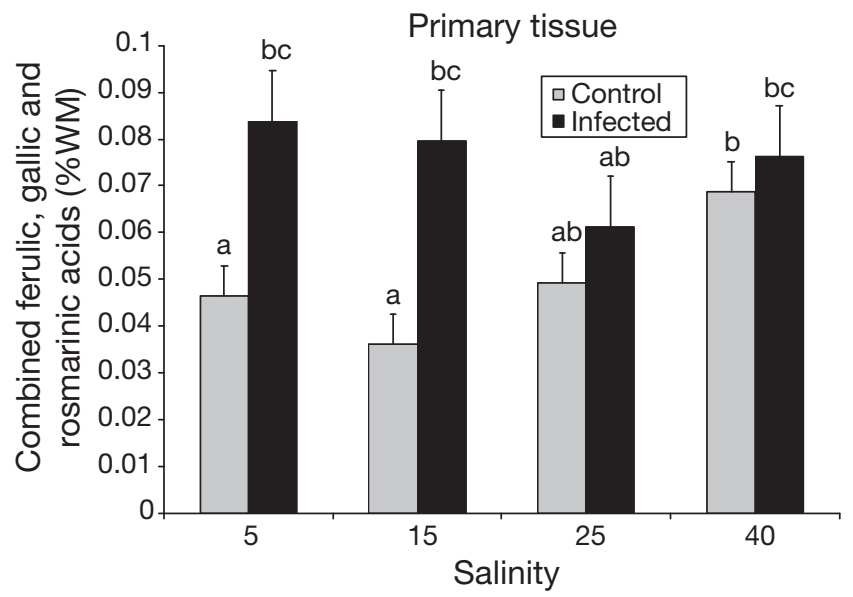

Fig. 7. Zostera marina. Gallic, ferulic and rosmarinic acid content $(\%)$ in wet mass (WM) of primary leaves from plants that received control vectors (control) or vectors inoculated with Labyrinthula zosterae (infected) in Expt 2. Letters above error bars indicate significant differences $(p<0.05$; mean \pm SE, $\mathrm{n}=3$ to 5 )

plants increased relative to the controls at salinities of 15 and 40 (Fig. 6). However, we did find a significant interaction between salinity and infection for the primary leaf (2-factor ANOVA, $p=0.04)$. Phenolic acids in the primary leaf of infected plants increased relative to the controls at salinities of 5 and 15, and the control plants had higher phenolic acids at a salinity of 40 than control plants kept at salinities of 5 and 15 (Fig. 7).

\section{DISCUSSION}

Necrotic lesions increased in area with increasing salinity, indicating that infection with Labyrinthula zosterae was influenced by salinity. The lack of distinc- tive black lesions in plants held at salinities of 5 and 10 supports previous observations that wasting disease is inhibited at lower salinities (Muehlstein et al. 1988, Short et al. 1988, Burdick et al. 1993). We did not see an upper salinity threshold above which salinity did not affect the spread of wasting disease. Lower salinities very likely have an inhibitory effect on the growth and pathogenicity of L. zosterae. Although some Labyrinthula spp. have shown the ability to survive a wide range of salinities, including freshwater (Porter 1990, Hülsmann \& Galil 2001), others are inhibited by low salinities. Sykes \& Porter (1973) found that an isolate of Labyrinthula sp. from Thalassia testudinum required high concentrations of sodium, most likely to aid in phosphate uptake. Siegenthaler et al. (1967) found a similar requirement for the related marine protist Thraustochytrium roseum. While L. zosterae may be able to survive in low salinities, the formation of ectoplasmic networks is inhibited at low salinities (Young 1943). Porter (1990) noted that the ectoplasmic network produced by L. zosterae is capable of decomposing microorganisms, so it is likely that its presence is necessary for the infection of seagrasses.

Another possible explanation for an increase in infection with increasing salinity is that the resistance of eelgrass to infection is decreased when the plant is stressed (Rasmussen 1977, Short et al. 1988, Vergeer \& den Hartog 1994). Brackish water populations of eelgrass show decreased growth, photosynthesis and overall vitality in full strength seawater (Kamermans et al. 1999, van Katwijk et al. 1999). Eelgrass used in this study came from a population exposed to monthly mean salinities that ranged from 14.5 to 15.5 , and the eelgrass grown in culture for Expt 2 was held at a salinity of 21.

However, phenolic acids, which have been hypothesized to play a role in resistance to infection by Labyrinthula zosterae (Vergeer \& Develi 1997), were not directly affected by salinity. Either the presence of an infection by Labyrinthula zosterae, or an interaction between infection and salinity, caused a significant change in phenolic acids in the secondary leaves, but salinity alone was not associated with a change in phenolic compounds. Phenolic compounds in eelgrass have not been previously observed to be affected by salinity (Vergeer et al. 1995), even though sulfated phenolic and flavonoid compounds are hypothesized to increase salt tolerance in some seagrasses including eelgrass (McMillan et al. 1980, Arnold \& Targett 2002), and an increase in phenolic compounds with increasing salinity has been observed in salt tolerant terrestrial plants (Siddiqui et al. 1996).

We did find a positive linear relationship between the production of phenolic acids and increasing lesion area in secondary leaves, implying an induction of 
phenolic acids in response to infection, which has been suggested by other studies (Vergeer et al. 1995, Vergeer \& Develi 1997). The tropical seagrass Thalassia testudinum also shows an increase in phenolic acids with Labyrinthula infection (Steele et al. 2005), although the increase is more localized, occurring only in tissue above the lesion. Steele et al. (2005) referred to this as pseudo-induction because they hypothesized that as the necrotic lesions increased in size, the flow of carbohydrates from the leaf tip to the base was disturbed, causing an accumulation of carbon and therefore phenolic compounds above the lesion. Unlike that in $T$. testudinum, the induction observed in eelgrass was not the result of pseudo-induction, as the production of phenolic compounds increased in a non-localized fashion within the secondary leaf in response to increased infection. Phenolic acid synthesis was also induced in tissue distant from the leaf that was inoculated with $L$. zosterae, indicating that the response is systemic. This systemic induction in the primary leaf and rhizome, however, was not linked to lesion size in the inoculated leaf, suggesting that induction in these tissues was in response to pathogen elicitors and not the presence of lesions. Other variable systemic responses have been reported in seagrasses. For example, Arnold et al. (2008) observed rapid accumulation of condensed tannins in the rhizome of $T$. testudinum but not in leaves following grazing of the leaves by sea urchins.

Induction of phenolic acid synthesis in response to infection, environmental stress and physical damage is widespread among plants (Levin 1971, Dixon \& Paiva 1995, Arnold et al. 2008), and phenolic acids can provide increased disease resistance to a plant (Levin 1971, Sarma \& Singh 2003). In eelgrass caffeic acid has been shown to increase in response to infection and to inhibit the growth of Labyrinthula zosterae in culture (Vergeer \& Develi 1997). In our study, gallic acid increased by $250 \%$; however, we have no evidence that gallic acid can inhibit an infection of L. zosterae. In fact, phenolic acids may not be good indicators of disease resistance in seagrasses (Jensen et al. 1998). In our 2 experiments the concentrations of phenolic acids were similar (Figs. 3 \& 4), but the lesion size was nearly 6 times greater in Expt 1 (at a salinity of 25; Figs. 1 \& 2). Phenolic acids tend not to accumulate but rather become glycosylated, form polymers or conjugate to other compounds (Levin 1971, Dixon \& Paiva 1995). In seagrasses, sulfated compounds from phenolic acid precursors have been shown to have antimicrobial properties (Todd et al. 1993, Jensen et al. 1998, Engle et al. 2006), and eelgrass may use similar or other phenolic compounds to increase resistance to L. zosterae. The differences in lesion size between the 2 experiments could reflect variation in such compounds or other disease responses to different growth conditions. Wasting disease has been reported to be less severe in young, rapidly growing leaves (Hily et al. 2002), which may explain the variation we observed between Expts 1 and 2, as plants used in Expt 1 were collected from a field population where they were subjected to variable conditions, whereas plants used in Expt 2 were grown in culture under constant conditions optimal for growth.

\section{CONCLUSION}

Lesion area clearly increases with increasing salinity, and salinity plays a major role in the ability of Labyrinthula zosterae to infect eelgrass. These findings suggest that salinity could have been an important factor in the diebacks and recovery of Zostera marina in the 1930s and the 1980s and illustrate the importance of low salinity habitats as refuge and for the re-growth of eelgrass populations. While the concentrations of phenolic acids increased with increasing lesion area, there is no direct evidence that they can impede the spread of an infection by $L$. zosterae. The differences in lesion size between our experiments suggest that eelgrass has other mechanisms to increase resistance to wasting disease.

Acknowledgements. We thank J. Benson, L. Hoffman, H. Bush, B. Russell, A. Boettcher and T. Arnold for all of their assistance, and the anonymous reviewers for their helpful comments. This work was supported by NSF-RUI grants to C.T. (OCE-0117582) and Sigma Xi Grants-in-Aid of Research.

\section{LITERATURE CITED}

Arnold TM, Targett NM (2002) Marine tannins: the importance of a mechanistic framework for predicting ecological roles. J Chem Ecol 28:1919-1934

Arnold TM, Tanner CE, Rothen M, Bullington J (2008) Wound-induced accumulations of condensed tannins in turtlegrass, Thalassia testudinum. Aquat Bot 89:27-33

Blakesley BA, Berns DM, Merello MF, Hall MO, Hyniova J (2001) The dynamics and distribution of the slime mold Labyrinthula sp. and its potential impacts on Thalassia testudinum populations in Florida. Tampa Bay Estuary Program, Technical Publication 01-01, St. Petersburg, FL, p 199-207. www.tbeptech.org/SeagrassProceedgs/fEmergingIssuses/1999blakesly.pdf

> Buchsbaum RN, Short FT, Cheney DP (1990) Phenolic-nitrogen interactions in eelgrass, Zostera marina L.: possible implications for disease resistance. Aquat Bot 37:291-297

Burdick DM, Short FT, Wolf J (1993) An index to assess and monitor the progression of wasting disease in eelgrass Zostera marina. Mar Ecol Prog Ser 94:83-90

den Hartog C (1970) The seagrasses of the world. NorthHolland Publishers, Amsterdam

den Hartog C (1987) 'Wasting disease' and other dynamic phenomena in Zostera beds. Aquat Bot 27:3-14

Dexter RW (1985) Changes in the standing crop of eelgrass, 
Zostera marina L., at Cape Ann, Massachusetts, since the epidemic of 1932. Rhodora 87:357-366

Dixon RA, Paiva NL (1995) Stress-induced phenylpropanoid metabolism. Plant Cell 7:1085-1097

Engel S, Puglisi MP, Jensen PR, Fenical W (2006) Antimicrobial activities of extracts from tropical Atlantic marine plants against marine pathogens and saprophytes. Mar Biol 149:991-1002

Giesen WBJT, Van Katwijk MM, den Hartog C (1990) Temperature, salinity, insolation and wasting disease of eelgrass (Zostera marina L.) in the Dutch Wadden Sea in the 1930's. Neth J Sea Res 25:395-404

Harrison PG (1982) Control of microbial growth and of amphipod grazing by water-soluble compounds from leaves of Zostera marina. Mar Biol 67:225-230

> Harrison PG, Durance C (1989) Seasonal variation in phenolic content of eelgrass shoots. Aquat Bot 35:409-413

> Hily C, Raffin C, Brun A, den Hartog C (2002) Spatio-temporal variability of wasting disease symptoms in eelgrass meadows of Brittany (France). Aquat Bot 72:37-53

Hülsmann N, Galil BS (2001) The effects of freshwater flushing on marine heterotrophic protists - implications for ballast water management. Mar Pollut Bull 42:1082-1086

Jensen PR, Jenkins KM, Porter D, Fenical W (1998) Evidence that a new antibiotic flavone glycoside chemically defends the sea grass Thalassia testudinum against zoosporic fungi. Appl Environ Microbiol 64:1490-1496

Kamermans P, Hemminga MA, de Jong DJ (1999) Significance of salinity and silicon levels for growth of a formerly estuarine eelgrass (Zostera marina) population (Lake Grevelingen, The Netherlands). Mar Biol 133:527-539

> Levin DA (1971) Plant phenolics: an ecological perspective. Am Nat 105:157-181

McMillan C, Zapata O, Escobar L (1980) Sulphated phenolic compounds in seagrasses. Aquat Bot 8:267-278

Milkova T, Petkova R, Christov R, Popov S, DimitrovaKonaklieva S (1995) Comparative study of the chemical composition of Zostera marina L. and Zostera nana Roth from the Black Sea. Bot Mar 38:99-101

Muehlstein LK, Porter D, Short FT (1988) Labyrinthula sp., a marine slime mold producing the symptoms of wasting disease in eelgrass, Zostera marina. Mar Biol 99:465-472

Muehlstein LK, Porter D, Short FT (1991) Labyrinthula zosterae sp. nov., the causative agent of wasting disease of eelgrass, Zostera marina. Mycologia 83:180-191

> Nicholson RL, Hammerschmidt R (1992) Phenolic compounds and their role in disease resistance. Annu Rev Phytopathol 30:369-389

Pinnerup SP (1980) Leaf production of Zostera marina L. at different salinities. Ophelia 1:219-224

Porter D (1990) Labyrinthulomycota. In: Margulis L, Corliss J, Melkonian M, Chapman D (eds) Handbook of protoctista. Jones \& Bartlett Publisher, Boston, MA, p 388-398

Quackenbush RC, Bunn D, Lingren W (1986) HPLC determination of phenolic acids in the water-soluble extract of Zostera marina L. (eelgrass). Aquat Bot 24:83-89

Raghukumar S (2002) Ecology of the marine protists, Labrinthulomycetes (Thraustochytrids and Labrinthulids). Eur J Protistol 38:127-145

Editorial responsibility: Kenneth Heck, Dauphin Island, Alabama, USA
Ralph PJ, Short FT (2002) Impact of the wasting disease pathogen, Labyrinthula zosterae, on the photobiology of eelgrass Zostera marina. Mar Ecol Prog Ser 226:265-271

Rasmussen E (1977) The wasting disease of eelgrass (Zostera marina) and its effects on environmental factors and fauna. In: McRoy CP, Helfferich C (eds) Seagrass ecosystems: a scientific perspective. Marcel Dekker, New York, p1-51

Ravn H, Pedersen MF, Andary J, Borum C, Anthoni U, Christophersen C, Nielsen PH (1994) Seasonal variation and distribution of two phenolic compounds, rosmarinic acid and caffeic acid, in leaves and roots-rhizomes of eelgrass (Zostera marina L.). Ophelia 40:51-61

Sarma BK, Singh UP (2003) Ferulic acid may prevent infection of Cicer arietinum by Sclerotium rolfsii. World J Microbiol Biotechnol 19:123-127

Short FT, Muehlstein LK, Porter D (1987) Eelgrass wasting disease: cause and recurrence of a marine epidemic. Biol Bull (Woods Hole) 173:557-562

Short FT, Ibelings BV, den Hartog C (1988) Comparison of a current eelgrass disease to the wasting disease in the 1930s. Aquat Bot 30:295-304

Siddiqui S, Gupta K, Yadav A, Mangal JL (1996) Soil salinity effect on soluble saccharides, phenol, fatty acid and mineral contents, and respiration rate of garlic cultivars. Biol Plant 38:611-615

Siegenthaler PA, Belsky MM, Goldstein S (1967) Phosphate uptake in an obligately marine fungus: a specific requirement for sodium. Science 155:93-94

Steele L, Caldwell M, Boettcher A, Arnold T (2005) Seagrasspathogen interactions: 'pseudo-induction' of turtlegrass phenolics near wasting disease lesions. Mar Ecol Prog Ser 303:123-131

Stevens NE, Ellis HR, Stevens RB (1950) Wasting and recovery of Zostera marina on the Atlantic coast of the United States. Plant Dis Rep 34:357-362

Sykes EE, Porter D (1973) Nutritional studies of Labyrinthula sp. Mycologia 65:1302-1311

Todd JS, Zimmerman RC, Crews P, Alberte RS (1993) The antifouling activity of natural and synthetic phenolic acid sulphate esters. Phytochemistry 34:401-404

van Katwijk MM, Schmitz GHW, Gasseling AP, van Avesaath PH (1999) Effects of salinity and nutrient load and their interaction on Zostera marina. Mar Ecol Prog Ser 190: $155-165$

- Vergeer LHT, den Hartog C (1994) Omnipresence of Labyrinthulaceae in seagrasses. Aquat Bot 48:1-20

Vergeer LHT, Develi A (1997) Phenolic acids in healthy and infected leaves of Zostera marina and their growthlimiting properties towards Labyrinthula zosterae. Aquat Bot 58:65-72

Vergeer LHT, Aarts TL, de Groot JD (1995) The 'wasting disease' and the effect of abiotic factors (light intensity, temperature, salinity) and infection with Labyrinthula zostereae on the phenolic content of Zostera marina shoots. Aquat Bot 52:35-44

Young EL (1943) Studies on Labyrinthula. The etiologic agent of the wasting disease of eel-grass. Am J Bot 30:586-593

Zapata O, McMillan C (1979) Phenolic acids in seagrasses. Aquat Bot 7:307-317

Submitted: June 22, 2007; Accepted: November 26, 2008 Proofs received from author(s): February 17, 2009 